\title{
A Study on Relationship between Financial Development and New Urbanization--Evidence from Urban Agglomeration in the Middle Reaches of the Yangtze River
}

\author{
Hao-Yang XU \\ School of Economics, Wuhan University of Technology, No. 122, Luo Shi Road, Hongshan District, \\ Wuhan, China \\ 982797692@qq.com
}

Keywords: Financial Development; New Urbanization; Urban Agglomeration

\begin{abstract}
This paper explores the relationship between financial development and new urbanization development in urban agglomeration in the middle reaches of the Yangtze River. After the unit root test, co-integration test, and the panel data model establishing, some conclusions are figured out. The results show that in the long term run, the level of financial deepening is significantly related with the urbanization development, but the coefficient is relatively small. And the deposit ratio and urbanization are significantly negatively related.
\end{abstract}

\section{Introduction}

With the development of industrialization, new urbanization is an important symbol of national modernization. New urbanization often contains the infrastructure construction, regional economic development and public services expanding. Then the financial support is critical. And with the Chinese economic development is more and more diversity, some new requirements are put forward for the financial supporting.

The government has issued the "National new urbanization plan (2014-2020)" in 2014. And the policy notes that we should focus on the urban agglomerations which are high efficiency concentration, large radiation, and functional complementation, then supporting the area or the nation economic growth. The urban agglomeration in the middle reaches of the Yangtze River is the critical part of the strategy of "rise of central China". Then it is of theoretical and practical significance to study on the relationship between financial development and new urbanization in this area.

The paper' sections are organized as follows. Section 2 describes the literature review for this research field. Section 3 is the empirically analysis. And the section 4 is the conclusions.

\section{Literature Review}

Pravesh Tamang (2013) selected 14 developing countries and 13 developed countries, to explore the Granger causality relationship between urbanization and economic development. And the results show that the degree of urbanization is the critical Granger cause for the economic development. And a country's economic status is an important factor in determining the direction of causality of this test. Ahmad N. Abdel-Rahman, Mohammad R. Safarzadeh and Michael Bruce Bottomley (2006) selected 35 developing countries as the research sample, results of time series and cross-sectional analysis indicate that the urbanization and economic growth was negatively correlated.

In China, many researchers have studied the relationship between the urbanization and financial supporting. However, the existing literatures rarely selected the urban agglomeration as the study sample. Xiu-Ping Li (2014) studied the financing status quo and the needs of new urbanization. He suggested that the models and infrastructures of financing should be improved. Zhou Liqun (2013) considers that the sound credit investment mechanism, the development of multi-level capital market, improvement of multi-sector communication mechanism is critical. Chen Wenxin (2013) establishes a evaluation system of urbanization and financial supporting, and analyzes the coordination of the two terms. Liu Yafeng (2013) chose the panel data of Gansu province, the 
empirically analysis results indicate that the two terms are negatively correlated. One of the reasons is that the current financial market cannot meet the financial service needs which are generated by the development of urbanization.

\section{Empirically Analysis}

\section{Data Selection and Description}

The existing literatures show that many indicators can represent the financial development. In this paper, we use the financial deepening and financial efficiency. Generally, the expression for the financial deepening is (M2 + stock market value + debt market value) / GDP. Due to the lack of relevant data of financial assets, we use (financial deposit + financial loans) / GDP to represent the financial deepening. We use FIR to represent it. The financial institution plays a critical role in financing and capital allocation, so this paper use the indicator deposit ratio to reflect the capacity of attracting the deposits into supporting the development of urbanization. We use LD to represent it.

This paper selects the population urbanization rate to measure the level of urbanization. And the equation of urbanization rate is urban population in one area / the total population in all areas. We use $\mathrm{CZH}$ to represent it.

In China, new urbanization concept is put forward in 2003, so this paper select the data in Hubei, Hunan, Jiangxi and Anhui provinces from 2003 to 2012. The data is from the "China Statistical Yearbook" and "China City Statistical Yearbook".

\section{Panel Data Model and Empirical Analysis}

Unit Root Test

We use LLC and PPF unit root test methods to test the null hypothesis. The results are shown as follows.

Table 1 The results of unit root test

\begin{tabular}{|l|l|l|l|}
\hline & LLC test & PPF test & Adopted / Rejected \\
\hline CZH & $-3.74480(0.0001)$ & $38.1132(0.0000)$ & Rejected \\
\hline FIR & $-4.20433(0.0000)$ & $24.9653(0.0016)$ & Rejected \\
\hline LD & $-6.06796(0.0000)$ & $25.1874(0.0014)$ & Rejected \\
\hline
\end{tabular}

Notes: The values in "()" are the p-values for the statistics test values. The null hypothesis of the unit root test is there is a unit root in the serial. The alternative hypothesis is there is no unit root in the serial.

The results in table 1 show that all the indicators serials pass the LLC unit root test and PPF unit root test. It indicates that they are all one-difference integration serials.

Co-integration Test

Table 2 The results if co-integration test

\begin{tabular}{|c|c|c|}
\hline Hypothesis & Statistic & Statistics value (P-value) \\
\hline H0: $\rho=1$ & Panel v-Statistic & $-1.040052(0.2323)$ \\
\cline { 2 - 3 } $\mathrm{H} 1:(\rho \mathrm{i}=\rho)<1$ & Panel rho-Statistic & $1.534782(0.1229)$ \\
\cline { 2 - 3 } & Panel PP -Statistic & $0.896406(0.2669)$ \\
\cline { 2 - 3 } & Panel ADF-Statistic & $2.236272(0.0327)$ \\
\hline \multirow{3}{*}{$\mathrm{H} 1:(\rho \mathrm{i}=\rho)<1$} & Group-rho- Statistic & $2.538014(0.0159)$ \\
\cline { 2 - 3 } & Group PP- Statistic & $1.117933(0.2136)$ \\
\cline { 2 - 3 } & Group ADF- Statistic & $2.714863(0.0100)$ \\
\hline
\end{tabular}

The results indicate that under the 5\% significant level, all the tests reject the null hypothesis. It 
means there is a significant co-integration relationship between the 3 serials.

Regression Analysis

(1) Hausman Test

The null hypothesis is that the model should choose the random effects model which is $L N C H Z_{i}=\alpha+v_{i}+L N F I R_{i} \boldsymbol{\beta}+L D_{\mathrm{i}} \eta+\mathbf{u}_{i}$

And the result is as follows.

\begin{tabular}{|c|c|c|c|}
\hline Test Summary & Chi-Sq. Statistic & Chi-Sq. d.f. & Prob. \\
\hline Cross-section random & 0.379771 & 2 & 0.8271 \\
\hline
\end{tabular}

Cross-section random effects test comparisons:

\begin{tabular}{crrrr} 
Variable & Fixed & Random & Var(Diff.) & Prob. \\
\hline \hline LNFIR? & 0.713718 & 0.649055 & 0.011116 & 0.5397 \\
LD? & -0.039063 & -0.032529 & 0.000119 & 0.5490 \\
\hline \hline
\end{tabular}

Figure 1 the results of Hausman test

The results show that the statistic value is 0.38 and p-value is 0.83 . It indicates that the null hypothesis is adopted under the 5\% significant level. Then we choose the random effect model.

(2) Model Form Determination

First we test the varying coefficient model. And the results are as follows.

\begin{tabular}{|c|c|c|c|c|}
\hline HB-LNFIR_HB & -0.176894 & 0.606928 & -0.291458 & 0.7728 \\
\hline HN-LNFIR_HN & -1.203600 & 0.876655 & -1.372946 & 0.1807 \\
\hline _JX-LNFIR_JX & 0.984396 & 0.495032 & 1.988551 & 0.0566 \\
\hline _AH--LNFIR_AH & 1.538647 & 0.452595 & 3.399608 & 0.0020 \\
\hline _HB-LD_HB & 0.008185 & 0.168776 & 0.048499 & 0.9617 \\
\hline HN-LD_HN & 0.155821 & 0.152793 & 1.019818 & 0.3165 \\
\hline _JX-LD_JX & -0.030948 & 0.131349 & -0.235618 & 0.8154 \\
\hline $\begin{array}{l}\text { Fixed Effects (Cross } \\
\text { AH }\end{array}$ & -0.104304 & 0.144779 & -0.720436 & 0.4772 \\
\hline _HB-C & 0.479201 & & & \\
\hline $\mathrm{HN}-\mathrm{C}$ & 0.728711 & & & \\
\hline JX-C & -0.392253 & & & \\
\hline AH-C & -0.815659 & & & \\
\hline
\end{tabular}

Figure 2 Variable coefficient model results

Then we test for the fixed-effect model. And the results are as follows. 


\begin{tabular}{|c|c|c|c|c|}
\hline \multicolumn{5}{|c|}{$\begin{array}{l}\text { Dependent Variable: LNCZH? } \\
\text { Method: Pooled Least Squares } \\
\text { Date: } 05 / 21 / 14 \text { Time: } 10: 15 \\
\text { Sample: } 20032012 \\
\text { Included observations: } 10 \\
\text { Cross-sections included: } 4 \\
\text { Total pool (balanced) observations: } 40\end{array}$} \\
\hline Variable & Coefficient & Std. Error & t-Statistic & Prob. \\
\hline C & -1.312605 & 0.176086 & -7.454351 & 0.0000 \\
\hline LNFIR? & 0.713718 & 0.296062 & 2.410702 & 0.0215 \\
\hline LD? & -0.039063 & 0.077634 & -0.503174 & 0.6181 \\
\hline \multicolumn{5}{|c|}{ Fixed Effects (Cross) } \\
\hline - $\mathrm{HB}-\mathrm{C}$ & 0.069001 & & & \\
\hline - $\mathrm{HN}-\mathrm{C}$ & 0.067930 & & & \\
\hline JX-C & -0.033906 & & & \\
\hline$-\mathrm{AH}-\mathrm{C}$ & -0.103026 & & & \\
\hline
\end{tabular}

Figure 3 fixed-effect model results

We then test for the constant parameter model. The results are as follows.

\begin{tabular}{|c|c|c|c|c|}
\hline & \multicolumn{4}{|c|}{$\begin{array}{l}\text { Dependent Variable: LNCZH? } \\
\text { Method: Pooled Least Squares } \\
\text { Date: } 05 / 21 / 14 \text { Time: } 10: 18 \\
\text { Sample: } 20032012 \\
\text { Included observations: } 10 \\
\text { Cross-sections included: } 4 \\
\text { Total pool (balanced) observations: } 40\end{array}$} \\
\hline $\begin{array}{l}\text { LNFIR? } \\
\text { LD? }\end{array}$ & $\begin{array}{r}0.373663 \\
-0.005452\end{array}$ & $\begin{array}{l}0.198252 \\
0.085142\end{array}$ & $\begin{array}{r}1.884789 \\
-0.064035\end{array}$ & $\begin{array}{l}0.0673 \\
0.9493\end{array}$ \\
\hline R-squared & 0.092379 & \multicolumn{2}{|c|}{ Mean dependent var } & -0.882240 \\
\hline Adjusted R-squared & 0.043318 & \multicolumn{2}{|c|}{ S.D. dependent var } & 0.122597 \\
\hline S.E. of regression & 0.119912 & \multicolumn{2}{|c|}{ Akaike info criterion } & -1.332081 \\
\hline Sum squared resid & 0.532018 & \multicolumn{2}{|c|}{ Schwarz criterion } & -1.205415 \\
\hline Log likelihood & 29.64162 & \multirow{2}{*}{\multicolumn{2}{|c|}{ Hannan-Quinn criter. }} & -1.286283 \\
\hline F-statistic & 1.882950 & & & 0.147014 \\
\hline Prob(F-statistic) & 0.166432 & & & \\
\hline
\end{tabular}

Figure 4 constant parameter model results

Then we can get the following equations.

$$
\begin{aligned}
& F_{1}=\frac{\left(S 2-S_{1}\right) / 9}{S_{1} / 28}=4.86 F_{2}=\frac{\left(S_{3}-S_{1}\right) / 6}{S_{1} / 28}=1.22 \\
& F_{\alpha 2}(6,28)=2.54 \text { and } F_{\alpha 1}(9,28)=2.24 \text {, so } F_{2}>2.54 .
\end{aligned}
$$

Then we reject the null hypothesis and choose the fixed-effect model. We can figure out the output equations as follows.

Hubei province: $L N C Z H_{\mathrm{i}}=-1.31+0.71 L N F I R_{i}-0.04 L D_{i}+0.069+\mathbf{u}_{i}$

Hunan province: $L N C Z H_{i}=-1.31+0.71 L N F I R_{i}-0.04 L D_{i}+0.068+\mathbf{u}_{i}$

Jiangxi province: $L N C Z H_{i}=-1.31+0.71 L N F I R_{i}-0.04 L D_{i}-0.033+\mathbf{u}_{i}$

Anhui province: $L N C Z H_{i}=-1.31+0.71 L N F I R_{i}-0.04 L D_{i}-0.103+\mathbf{u}_{i}$ 


\section{Conclusions}

The empirically analysis results show that in the long term run, the level of financial deepening is significantly related with the urbanization development. However, the coefficient is 0.71 , which is relatively small. The results of the test for deposit ratio and urbanization indicate that the two terms have significantly negative relation. And in the area of Urban Agglomeration in the Middle Reaches of the Yangtze River, the level of urbanization in Hubei province is relatively higher and that in Anhui province is relatively lower.

\section{Acknowledgement}

This paper was financially supported by the Fundamental Research Funds for the Central Universities (2014-JJ-A1-02).

\section{References}

[1] Pravesh Tamang,Urbanisation and Economic Growth: Investigating Causality [J]. Econometircs, 2013(3).41-47

[2] Rahaman, A.N., M.R. Safarzadeh and M.B. Bottomley, Economic Growth and Urbanisation: A Cross-Section and Time-series Analysis of Thirty-five Developing Countries[J].International Review of Economics, 2006,vol.53(3).334-348

[3] Xiu-Ping Li promoting financial support for research in new urbanization process [J] Chinese commerce, 2014 (1) 128-129.

[4] Zhou Liqun. Urbanization process in China's financial support path analysis. [J]. Northern Economy and Trade, 2013 (10) 